\title{
Preparation and adsorptive application of novel superparamagnetic zirconia material
}

\author{
Chiung-Fen Chang ${ }^{\mathrm{a}, *}$, Ching-Yuan Chang ${ }^{\mathrm{b}}$, Tzu-Ling Hsu ${ }^{\mathrm{b}}$ \\ a Department of Environmental Science and Engineering, Tunghai University, Taichung 407, Taiwan \\ ${ }^{\mathrm{b}}$ Graduate Institute of Environmental Engineering, National Taiwan University, Taipei 106, Taiwan
}

\section{A R T I C L E I N F O}

\section{Article history:}

Received 15 February 2008

Received in revised form 4 June 2008

Accepted 5 June 2008

Available online 11 June 2008

\section{Keywords:}

Superparamagnetism

Zirconia

Sol-gel method

Adsorption isotherm

Sulfate

\begin{abstract}
A B S T R A C T
A novel superparamagnetic zirconia $\left(\mathrm{ZrO}_{2} / \mathrm{SiO}_{2} / \mathrm{Fe}_{3} \mathrm{O}_{4}, \mathrm{SPMZ}\right)$ material has been successfully synthesized via three sequential steps: chemical precipitation of magnetite, sol-gel coating of silica and sol-gel covering of zriconia. The physicochemical properties were characterized with $\mathrm{N}_{2}$ adsorption at $77 \mathrm{~K}$, scanning electron microscopy with energy-dispersive X-ray spectroscopy (SEM/EDX), superconducing quantum interference device (SQUID), powder X-ray diffraction (XRD), thermogravimetric analysis (TGA) and electrophoresis. SEM/EDX showed that zirconium is abundant on the surface with high atomic percent and the size of the aggregate is approximately smaller than $100 \mathrm{~nm}$. Powder XRD illustrated the coexistence of tetragonal and monoclinic crystals. TGA indicated that conversion rate of pre-SPMZ before final calcination is affected by pyrolysis temperature. The adsorption behavior of sulfate on SPMZ from aqueous solution was examined as an index of adsorptive application. The removal efficiency of sulfate via adsorption is rather sensitive to the $\mathrm{pH}$ value of the solution in the range of 4-5.8. The further adsorption of sulfate on SPMZ is restrained as the $\mathrm{pH}$ value of solution reaches the point of zero charge $\mathrm{pH}_{\mathrm{PZC}}$ of SPMZ. The adsorption capacity of sulfate on SPMZ under a fixed $\mathrm{pH}$ value of 4 can be comparable to that of commercially nanopowder of zirconia. Furthermore, the adsorption rate of sulfate on SPMZ is rather fast in $1 \mathrm{~min}$ and then gradually slows down reaching the adsorption equilibrium. The liquid-solid separation can be easily carried out via the magnetic separation.
\end{abstract}

(C) 2008 Elsevier B.V. All rights reserved.

\section{Introduction}

The sorption or ion exchange process can effectively remove specific species from the fluid even under low concentration [1-11]. Over the past few decades of research on the science and technology of adsorption process, the adsorption mechanism and kinetics have been progressively and tremendously understood. However, the adsorption behavior of various specific pairs of adsorbents and adsorbates cannot be well known and predicted prior to experimental tests. Recently, the development of nano-size materials has been flourishing due to the novel behavior and high potential of application. Since adsorption process occurs at the interface of solid and fluid, the nano-sized adsorbents of high specific external surface areas are expected to be beneficial to the adsorption kinetics and capacity. However, ultra-fine particles exhibit the difficulty of operation subject to high pressure drop for the packed-bed reactor and the problem of solid/liquid separation for the completely

\footnotetext{
* Corresponding author at: Tunghai University, P.O. Box 818, Taichung 407, Taiwan. Tel.: +886 4 23590121x3052; fax: +886 423594276 .

E-mail address: cfchang@thu.edu.tw (C.-F. Chang).
}

stirred tank reactor (CSTR). In order to overcome the separation problem of CSTR, magnetic separation technology combined with the modification of specific functional groups on the magnetic particle has high potential for the application in heterogeneous system with its easy control and effectiveness [12-15].

The zirconium oxide (zirconia) has high chemical, corrosion and temperature resistances so that it has been widely applied on the catalysis, sorption, ceramic and fuel cell [16-18]. The surface of zirconia has strong interaction with Lewis bases and can be dynamically and permanently modified for the adsorptive applications [19]. The preparation of zirconia via sol-gel method has been investigated and the structure can be designed by means of templates $[20,21]$. Furthermore, the crystalline structures of resulting materials are significantly affected by the catalytic acid used in the sol-gel process and the annealing temperature $[22,23]$.

Sulfate is commonly found in the agricultural area due to the activity of fertilization and amendment of gypsum [24]. In addition, it also exists in environmental water and industrial wastewater $[25,26]$. The investigation on the adsorption of sulfate on soils and adsorbent materials showed that the sulfate are adsorbed only on the surface of positive charge [27] and the formation of outersphere or inner-sphere complexes with the surface of adsorbent 
depends on the pH value of the solution [28]. Moreover, the competitive adsorption ability of sulfate decreases with increasing initial concentrations of exchangeable counter anions [29]. Nevertheless, there have been few studies related to the adsorption of sulfate on zirconia, especially magnetic zirconia. Therefore, the purpose of this study was to synthesize a novel superparamagnetic zirconia via sol-gel method and apply it to remove sulfate from aqueous solutions. The physicochemical properties of super-paramagnetic zirconia were characterized with accelerated surface area measurement and porosimetry systems, scanning electron microscopy with energy-dispersive X-ray spectroscopy (SEM/EDX), superconducing quantum interference device (SQUID), powder X-ray diffraction (XRD), thermogravimetric analysis (TGA) and electrophoresis. The adsorption behavior of sulfate on the resulting superparamagnetic zirconia from aqueous solutions was examined.

\section{Materials and methods}

\subsection{Synthesis of superparamagnetic zirconium-type adsorbents}

The superparamagnetic zirconium-type adsorbent was prepared in three sequential steps: (1) the formation of magnetic core $\left(\mathrm{Fe}_{3} \mathrm{O}_{4}, \mathrm{M}\right)$ by means of the chemical precipitation; (2) coating with silica film to form the magnetic silica-coated carrier $\left(\mathrm{SiO}_{2} / \mathrm{Fe}_{3} \mathrm{O}_{4}\right.$, $\mathrm{SM}$ ) via the sol-gel method; and (3) the formation of superparamagnetic zirconia $\left(\mathrm{ZrO}_{2} / \mathrm{SiO}_{2} / \mathrm{Fe}_{3} \mathrm{O}_{4}\right.$, denoted as SPMZ) adopting the sol-gel technique. The magnetite was synthesized from ferric and ferrous chloride salts at a stoichiometric ratio of $2: 1$ via the addition of ammonia as precipitator in an inert atmosphere and under vigorous mixing. After mixing for $3 \mathrm{~min}$ at a temperature of $353 \mathrm{~K}$, the magnetite $M$ produced was separated from the solution by means of a magnet and washed several times with distilled water. The obtained magnetite was subsequently placed in the admixture, which was composed of ammonium hydroxide, isopropanol, ultrapure water and tetraethylorthosilicates $\left(\mathrm{Si}\left(\mathrm{OC}_{2} \mathrm{H}_{5}\right)_{4}, \mathrm{TEOS}\right)$. The ratio of isopropanol:water: $\mathrm{NH}_{4} \mathrm{OH}$ (25 vol.\%):TEOS was 30:2:7.8:1 at a total volume of $2 \mathrm{dm}^{3}$. After strong mixing for $5 \mathrm{~h}$ at a temperature of $313 \mathrm{~K}$, the magnetic silica-coated particle was dried with infrared-ray lamp for overnight. It was then calcinated under $673 \mathrm{~K}$ for $8 \mathrm{~h}$ to obtain magnetic silica-coated carrier of SM. The calcined SM was then further contacted with the other admixture, which comprised the nitric acid, isopropanol, ultra-pure water and Zirconium (IV) tert-butoxide $\left(\mathrm{Zr}\left(\mathrm{OC}\left(\mathrm{CH}_{3}\right)_{3}\right)_{4}\right)$. The volumetric ratio of isopropanol:water:nitric acid: $\mathrm{Zr}\left(\mathrm{OC}\left(\mathrm{CH}_{3}\right)_{3}\right)_{4}$ was 88:3:1:21 at a total volume of $130 \mathrm{~cm}^{3}$. After vigorous mixing for $5 \mathrm{~h}$ at temperature of $313 \mathrm{~K}$, the obtained particle was dried with infrared-ray lamp for overnight (denoted as pre-SPMZ). Then, the magnetic particle of pre-SPMZ was calcinated under $673 \mathrm{~K}$ for $4 \mathrm{~h}$ to obtain superparamagnetic zirconium-type adsorbent of SPMZ.

\subsection{Characterization of physicochemical properties}

The accelerated surface area measurement and porosimetry systems adopting nitrogen adsorption (ASAP 2010, Micromeritics, Norcross, GA, USA) were employed to determine the surface area and porosity of the particles. The analysis of SEM/EDX was used to illustrate the structural properties of different particles with equipments of Hitachi S-2400 with Kevex Delta class 80000 EDS (Hitachi, Tokyo, Japan). Magnetic property of resulting materials was performed by means of a SQUID magnetometer (Model: MPMS7, Quantum Design Company, San Diego, CA, USA). The crystal structure of the resulting particles were examined, and confirmed using powder XRD analyzer (MXP diffraction collector, MAC Science, Kouhoku-ku, Yokohama city, Japan) with $\mathrm{Cu} \mathrm{K} \alpha$ (with wavelength $\lambda=1.5418 \AA$ ), and the Joint Committee on Powder Diffraction Standards (JCPDS) database, respectively. The relation between the weight loss and pyrolysis temperature of the pre-SPMZ particles was investigated using TGA (TGA-51, Shimadzu, Nakagyo-ku, Kyoto, Japan). The electrophoreses (i.e., zeta potentials) of SPMZ at various $\mathrm{pH}$ values under ionic strength of 0.01 and $0.1 \mathrm{~N} \mathrm{NaNO}_{3}$ were determined using a Zetasizer 3000 (Malvern Instruments, Worcestershire, United Kingdom).

\subsection{Adsorption of sulfate}

The bottle-point method and completely stirred tank reactor (CSTR) were used to obtain the data of adsorption isotherms of sulfate on SPMZ. The former was adopted for the adsorptive experiments without $\mathrm{pH}$ control, while the latter was designed to determine the adsorption isotherm under fixed $\mathrm{pH}$ value of 4 controlled using the solutions of $0.1 \mathrm{~N} \mathrm{NaOH}$. The ratio of the dosage of SPMZ to the volume of solution was kept at $2 \mathrm{~kg} \mathrm{~m}^{-3}$. The initial concentrations of sulfate at various levels were specially selected to yield applicable adsorption isotherms. The sulfate concentrations were determined by means of using 790 Personal IC (Metrohm AG, Herisau, Switzerland) with the eluent composition of $1.8 \mathrm{M} \mathrm{Na}_{2} \mathrm{CO}_{3}$ with $1.7 \mathrm{M} \mathrm{NaHCO}_{3}$. The specific amount adsorbed was calculated from

$Q_{e}=\left(C_{0}-C_{e}\right) \times \frac{V_{\mathrm{L}}}{W_{S}}$

where $q_{\mathrm{e}}$ is the adsorbate loading $\left(\mathrm{g} \mathrm{kg}^{-1}\right)$ in the solid at equilibrium; $C_{0}, C_{\mathrm{e}}$ are the initial and the equilibrium concentrations of sulfate $\left(\mathrm{g} \mathrm{m}^{-3}\right)$, respectively; $V_{\mathrm{L}}$ is the volume of the aqueous solution; and $W_{\mathrm{S}}$ is the mass ( $\mathrm{g}$ ) of adsorbents used in the experiments.

\section{Results and discussion}

\subsection{Appearance and magnetization of magnetic zirconia}

The Brunauer-Emmett-Teller (BET) surface area and various porous volumes of SPMZ are shown in Table 1 . The total pore $\left(V_{\mathrm{t}}\right)$, micro-pore $\left(V_{\mathrm{i}}\right)$, meso-pore $\left(V_{\mathrm{e}}\right)$, and macro-pore $\left(V_{\mathrm{a}}\right)$ volumes are $0.1651,0.0015,0.1231$, and $0.0405 \mathrm{~cm}^{3} \mathrm{~g}^{-1}$, respectively, interpreting that the meso-pore volume contributes most of the total pore volume. The adsorption and desorption isotherms of $\mathrm{N}_{2}$ at $77 \mathrm{~K}$ on the resulting SPMZ are illustrated in Fig. 1. The adsorbed amount of nitrogen on SPMZ increases with the increasing relative pressure, which belongs to Type II of BDDT (Brunauer-Deming-Deming-Teller) classification [30]. The material pertaining to Type II of BDDT classification is approximately non-, meso- or macro-porous powder [31]. Thus, the results of Fig. 1 are consistent with those of Table 1.

The SEM picture of resulting material of SPMZ is shown in Fig. 2. The appearance of particle is rather uniform. However, particles

Table 1

Physical properties of super-paramagnetic zirconia $\left(\mathrm{ZrO}_{2} / \mathrm{SiO}_{2} / \mathrm{Fe}_{3} \mathrm{O}_{4}, \mathrm{SPMZ}\right)$ obtained from nitrogen adsorption experiments

\begin{tabular}{|c|c|}
\hline Property & SPMZ \\
\hline $\mathrm{BET}^{\mathrm{a}}$-specific surface area $\left(\mathrm{m}^{2} \mathrm{~g}^{-1}\right)$ & 79.60 \\
\hline Pore volume $\left(\mathrm{cm}^{3} \mathrm{~g}^{-1}\right)$ total $\left(V_{\mathrm{t}}\right)$ & 0.1651 \\
\hline Micro-pore $\left(V_{\mathrm{i}}\right)$ & 0.0015 \\
\hline Meso-pore ${ }^{\mathrm{b}}\left(V_{\mathrm{e}}\right)$ & 0.1231 \\
\hline Macro-pore $^{\mathrm{b}}\left(V_{\mathrm{a}}\right)$ & 0.0405 \\
\hline
\end{tabular}

a BET: Brunauer-Emmett-Teller.

b Calculated using $V_{\mathrm{t}}-V_{\mathrm{i}}=V_{\mathrm{e}}+V_{\mathrm{a}}$, with Barrett, Joyner and Hanlenda (BJH) adsorption pore distribution, which gives the proportions of mesopore to macropore volumes. 


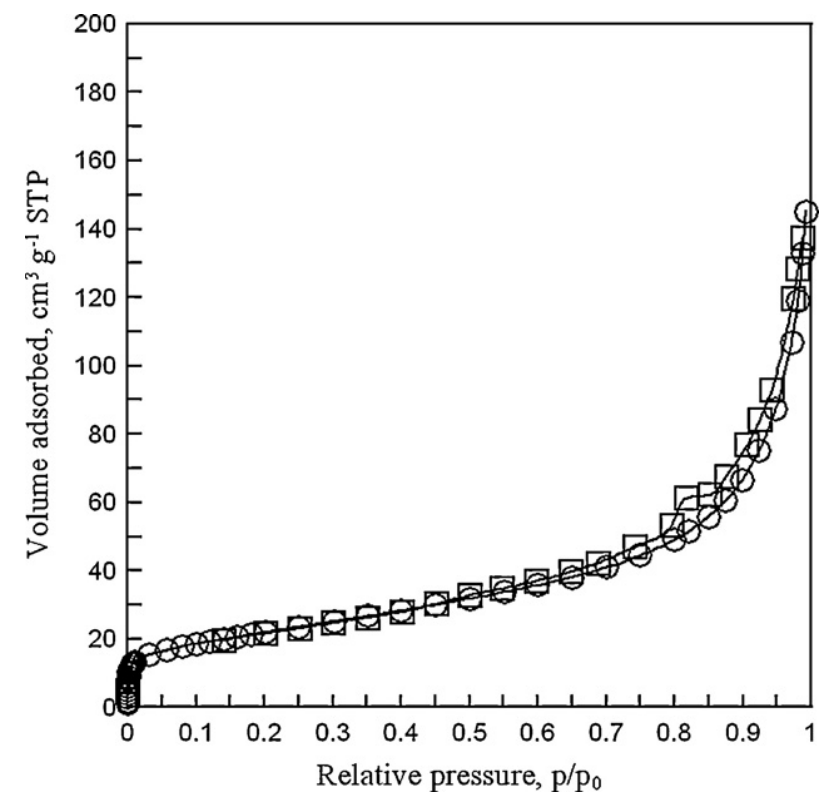

Fig. 1. Adsorption $(\bigcirc)$ and desorption $(\square)$ isotherms of $N_{2}$ at $77 \mathrm{~K}$ on superparamagnetic zirconia $\left(\mathrm{ZrO}_{2} / \mathrm{SiO}_{2} / \mathrm{Fe}_{3} \mathrm{O}_{4}, \mathrm{SPMZ}\right)$.

tend to aggregate so that it is difficult to determine the actual size of the particle. Nevertheless, the size of the aggregate is apparently below $100 \mathrm{~nm}$. Combined with the results of nitrogen adsorption mentioned above, the meso-pore volume seems to represent the void between the aggregates rather than the pores between the walls in particles. Fig. 3 and Table 2 illustrate the SEM/EDX spectra and atomic percent of various elements on the surface of SPMZ, indicating that high atomic percent of zirconium assembles on surface.

The saturation magnetization $\left(M_{\mathrm{S}}\right)$ of various resulting materials is presented in Fig. 4. Because of the zero coercive force and being free of hysteresis, all the magnetic particles obtained in this study are superparamagnetic. The values of $M_{\mathrm{S}}$ of magnetite $\mathrm{M}$ of $\mathrm{Fe}_{3} \mathrm{O}_{4}$, magnetic silica-coated carrier $\mathrm{SM}$ of $\mathrm{SiO}_{2} / \mathrm{Fe}_{3} \mathrm{O}_{4}$ and $\mathrm{SPMZ}$

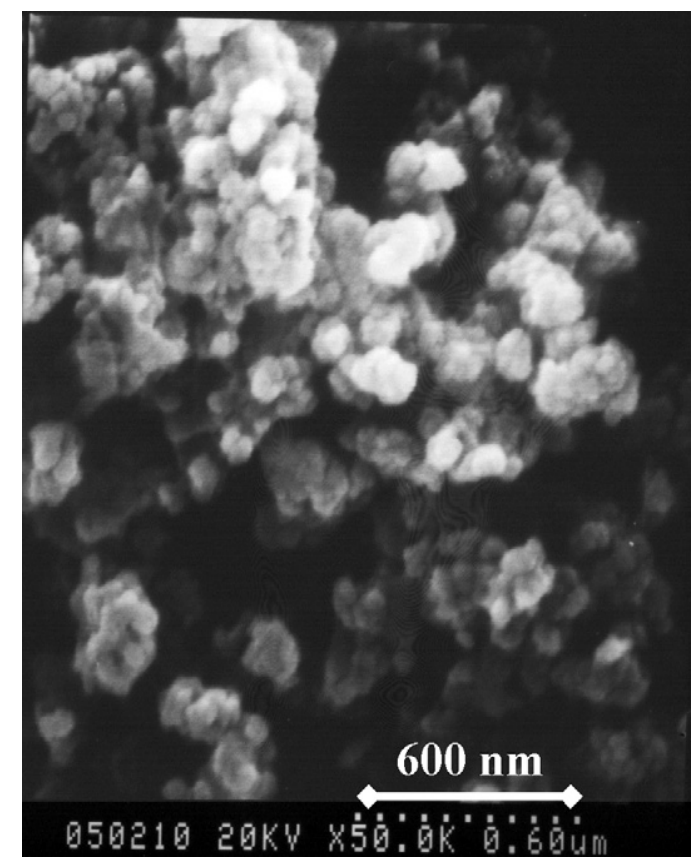

Fig. 2. SEM picture of SPMZ.
Table 2

The atomic percent of various elements on the surface of SPMZ from the analysis of EDX

\begin{tabular}{lc}
\hline Element & Atomic percent (\%) \\
\hline $\mathrm{Si}$ & 33.57 \\
$\mathrm{Fe}$ & 23.99 \\
$\mathrm{Zr}$ & 42.44 \\
Total & 100 \\
\hline
\end{tabular}

of $\mathrm{ZrO}_{2} / \mathrm{SiO}_{2} / \mathrm{Fe}_{3} \mathrm{O}_{4}$ synthesized in this study are 56.5, 21.7 and $7.1 \mathrm{emu} \mathrm{g}^{-1}$, respectively. According to the values of $M_{\mathrm{S}}$, the weight content of magnetite in SM (i.e., 38 wt.\%) and SPMZ (i.e., 13 wt.\%) can be calculated under the assumption that the magnetism is only contributed by magnetite.

\subsection{Crystalline structure and thermogravimetric analysis}

The crystalline structure of SPMZ was determined via powder XRD spectra, as illustrated in Fig. 5 . The characteristic peaks at specific angle (2 $2 \theta)$ of SPMZ are conformed using JCPDS database to ensure the crystallite. The results show that the crystallite of SPMZ is composed of both tetragonal $\left(\mathrm{T}-\mathrm{ZrO}_{2}\right)$ and monoclinic $\left(\mathrm{M}-\mathrm{ZrO}_{2}\right)$ types, of which the main peaks are at $2 \theta$ of 30,35 and 50 for $\mathrm{T}-\mathrm{ZrO}_{2}$, and of 24, 28 and 32 for $\mathrm{M}-\mathrm{ZrO}_{2}$, respectively. Therefore, the SPMZ synthesized in this study possesses both tetragonal and monoclinic crystals.

The residual mass fractions $\left(M_{\mathrm{I}}=W_{\mathrm{t}} / W_{0}\right.$ and $M=\left(W_{\mathrm{t}}-W_{\mathrm{f}}\right) /$ $\left.\left(W_{0}-W_{\mathrm{f}}\right)\right)$ and conversion $(X=1-M)$ of pre-SPMZ particles during the thermal decomposition under nitrogen gas applying TGA are expressed in a normalized basis, where $W_{\mathrm{t}}, W_{0}$ and $W_{\mathrm{f}}$ represent the masses of sample at time $t$, and initial and final states, respectively. The variations of $M$ and $M_{\mathrm{I}}$ with pyrolysis temperature $(T)$ at a fixed heating rate (HR) of $10 \mathrm{~K} \mathrm{~min}^{-1}$ for pre-SPMZ are presented in Fig. 6 . The mass of pre-SPMZ decreases slowly with increasing $T$ and retains the final mass of about $90 \%$ of the initial mass. The mass change of pre-SPMZ with $T$ is very low when $T$ is greater than $963 \mathrm{~K}$. The variation of instantaneous decomposition rate $(r=\mathrm{d} X / \mathrm{d} t)$ with $T$ at a HR of $10 \mathrm{~K} \mathrm{~min}^{-1}$ for thermal decomposition of pre-SPMZ particles under inert atmosphere of nitrogen is illustrated in Fig. 7. The decomposition occurs mainly in the temperature range of $400-700 \mathrm{~K}$, where the peaks appear at temperatures of about 440 and $640 \mathrm{~K}$, respectively. The mass loss related to the peak at $440 \mathrm{~K}$ possibly involves the desorption of free water and the loss of un-hydrolyzed carbonaceous residues of the organometallic precursors [23,32]. The reactions between 500 and $700 \mathrm{~K}$ with a main peak at $640 \mathrm{~K}$ mainly involve the transformation of $\mathrm{Zr}(\mathrm{OH})_{4}$ into $\mathrm{ZrO}_{2}$ and the further burning off of carbonaceous residues $[22,23,32]$. An overall reaction equation of transformation may be expressed as [23]:

$2 \mathrm{Zr}(\mathrm{OH})_{4} \rightarrow \mathrm{ZrO}_{2}(\mathrm{~T}$, tetragonal $)+\mathrm{ZrO}_{2}(\mathrm{M}$, monoclinic $)+4 \mathrm{H}_{2} \mathrm{O}$

The decomposition at a temperature higher than $700 \mathrm{~K}$ may be mainly due to the dehydration and de-hydroxylation of silanol group $(\mathrm{Si}-\mathrm{OH})[33,34]$ and the conversion of crystalline structure from $\mathrm{T}-\mathrm{ZrO}_{2}$ to $\mathrm{M}-\mathrm{ZrO}_{2}$, for which both crystals are verified to coexist in SPMZ via XRD spectra.

\subsection{Zeta potential}

As far as the adsorption of ionic species is concerned, electrostatic force, arisen from the surface of adsorbents and ionic adsorbate, plays a critical role on the adsorption capacity. The zeta 


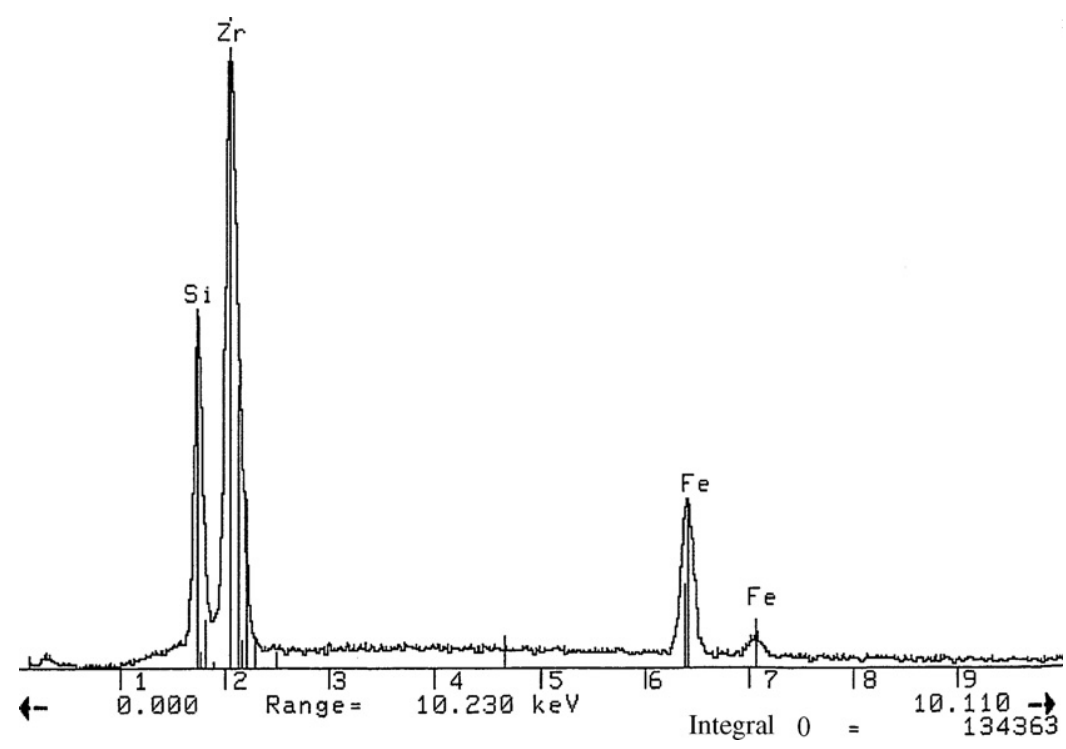

Fig. 3. EDX spectra of SPMZ.

potentials under various $\mathrm{pH}$ values were calculated from the results of electrophoreses of SPMZ, as illustrated in Fig. 8.

The results show that the point of zero charge $\left(\mathrm{pH}_{\mathrm{PZC}}\right)$ of SPMZ is around 5.8. Under the ionic strength of $0.1 \mathrm{~N}$, a small decrease or

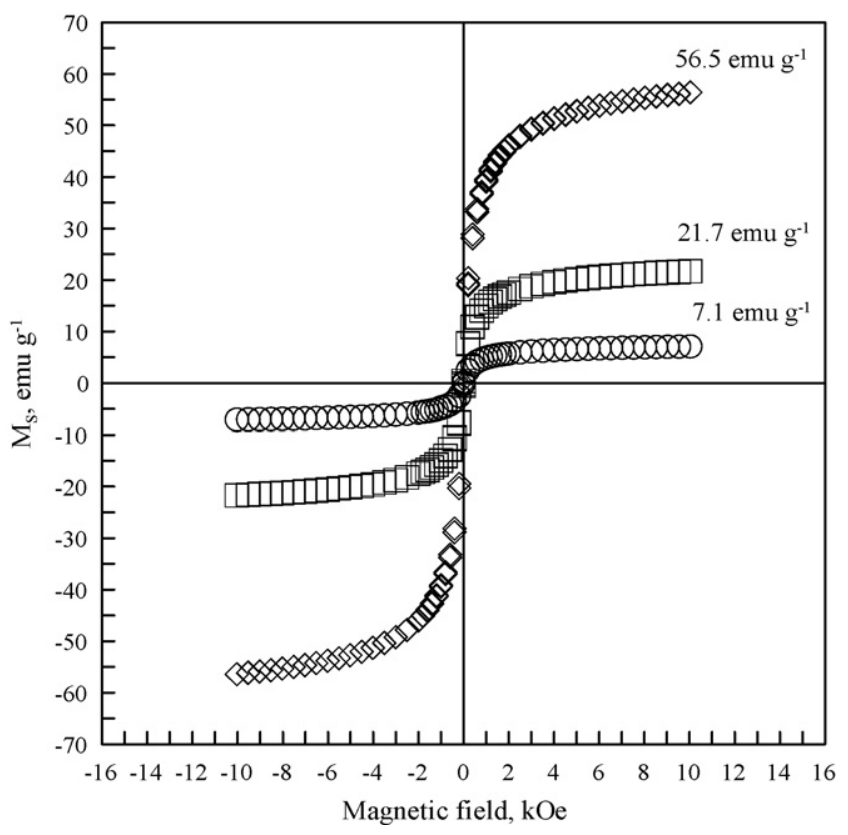

Fig. 4. Magnetization $\left(M_{S}\right)$ curves of various magnetic particles. $\square$, $\square$ and $\bigcirc$ : Magnetite $\mathrm{M}\left(\mathrm{Fe}_{3} \mathrm{O}_{4}\right)$, magnetic silica-coated carrier $\mathrm{SM}\left(\mathrm{SiO}_{2} / \mathrm{Fe}_{3} \mathrm{O}_{4}\right)$ and SPMZ.

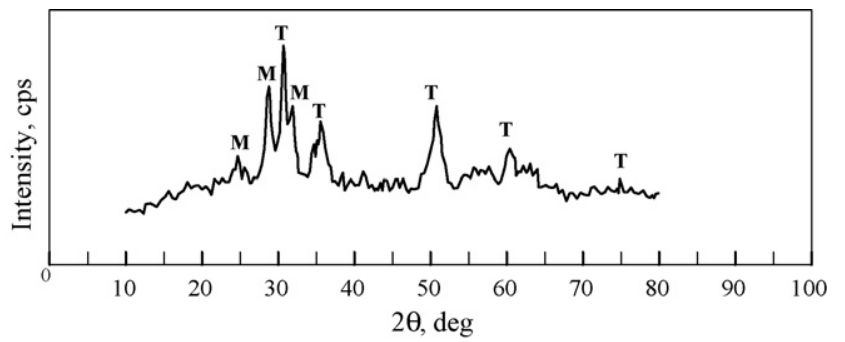

Fig. 5. Powder XRD patterns of SPMZ. T, M: Tetragonal and monoclinic types of crystallites of SPMZ. increase of $\mathrm{pH}$ value around $\mathrm{pH}_{\mathrm{PZC}}$ results in a rapidly sharp increase or decrease of zeta potential of SPMZ, interpreting that the surface potential of SPMZ is sensitive to the $\mathrm{pH}$ value of the solutions under higher ionic strength. For the following adsorptive experiments, the $\mathrm{pH}$ value of solution is supposed to be less than the $\mathrm{pH}_{\mathrm{PZC}}$ ( $\mathrm{pH}$ value of 5.8), which leads to the surface possessing positive charges, so as to facilitate the adsorption capacity of anionic species of sulfate.

\subsection{Adsorption capacity of sulfate on SPMZ}

\subsubsection{Effect of equilibrium $\mathrm{pH}$ value on adsorption capacity}

The adsorption of ionic species on adsorbents is particularly affected by the $\mathrm{pH}$ value of solutions due to the electrostatic attraction or repulsion between adsorbents and adsorbates. Therefore, the effect of $\mathrm{pH}$ value on the adsorption capacity of sulfate on SPMZ

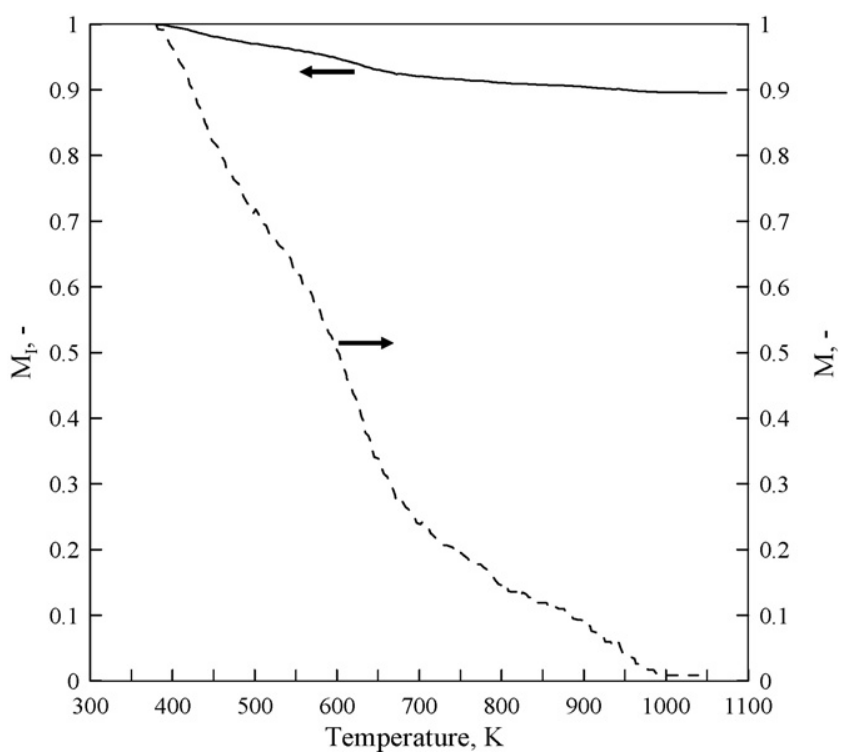

Fig. 6. Relationship between residual mass ratio (- for $M_{\mathrm{I}}$ and --- for $M$ ) of pre-SPMZ particles and pyrolysis temperature $(T)$ at a fixed heating rate (HR) of $10 \mathrm{~K} \mathrm{~min}^{-1}$ for thermal decomposition under inert atmosphere of nitrogen. $M_{\mathrm{I}}=W_{\mathrm{t}} / W_{0}$ and $M=\left(W_{\mathrm{t}}-W_{\mathrm{f}}\right) /\left(W_{0}-W_{\mathrm{f}}\right) . W_{\mathrm{t}}, W_{0}$ and $W_{\mathrm{f}}$ : Masses of sample at time $t$, and initial and final states, respectively. 


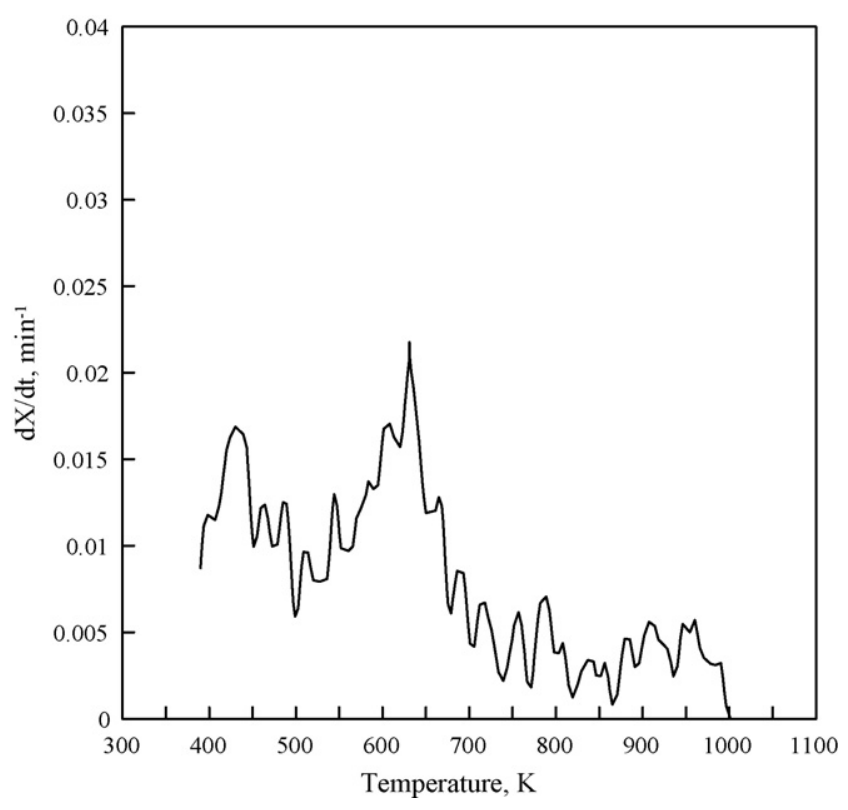

Fig. 7. Variation of instantaneous decomposition rate $(r=\mathrm{d} X / \mathrm{d} t)$ with $\mathrm{T}$ at a HR of $10 \mathrm{~K} \mathrm{~min}^{-1}$ for thermal decomposition of pre-SPMZ particles under inert atmosphere of nitrogen. $X=1-M$.

was firstly investigated at the initial $\mathrm{pH}$ value of 4 , as illustrated in Fig. 9. The equilibrium $\mathrm{pH}$ value $\left(\mathrm{pH}_{\mathrm{e}}\right)$ increases with increasing initial concentration $\left(C_{0}\right)$ and then reaches the plateau (i.e., $\mathrm{pH}_{\mathrm{e}}=5.8$ ). Depending on the $\mathrm{pH}_{\mathrm{e}}$ value, the adsorption capacity at various $C_{0}$ can be further divided into two groups: $\mathrm{GI}\left(C_{0}\right.$ of $1-7 \mathrm{~g} \mathrm{~m}^{-3}, \mathrm{pH}_{\mathrm{e}}$ of about 4.2$)$ and GII $\left(C_{0}=13.5-106 \mathrm{~g} \mathrm{~m}^{-3}, \mathrm{pH}_{\mathrm{e}}\right.$ of about 5-5.8). The adsorption capacity sharply increases with increasing $C_{0}$ as $\mathrm{pH}_{\mathrm{e}}$ is around 4.2 in GI, while gradually increases as $\mathrm{pH}_{\mathrm{e}}$ increases from 5 to 5.8 , reaching the plateau in GII. The maximum $\mathrm{pH}_{\mathrm{e}}$ is at 5.8 in GII, which is almost equal to the $\mathrm{pH}_{\mathrm{PZC}}$, interpreting that further adsorption of sulfate on SPMZ is suppressed as the $\mathrm{pH}$ value of solution reaches the $\mathrm{pH}_{\mathrm{PZC}}$ of SPMZ. The observation is similar to the study on the adsorption of sulfate on the non-magnetic par-

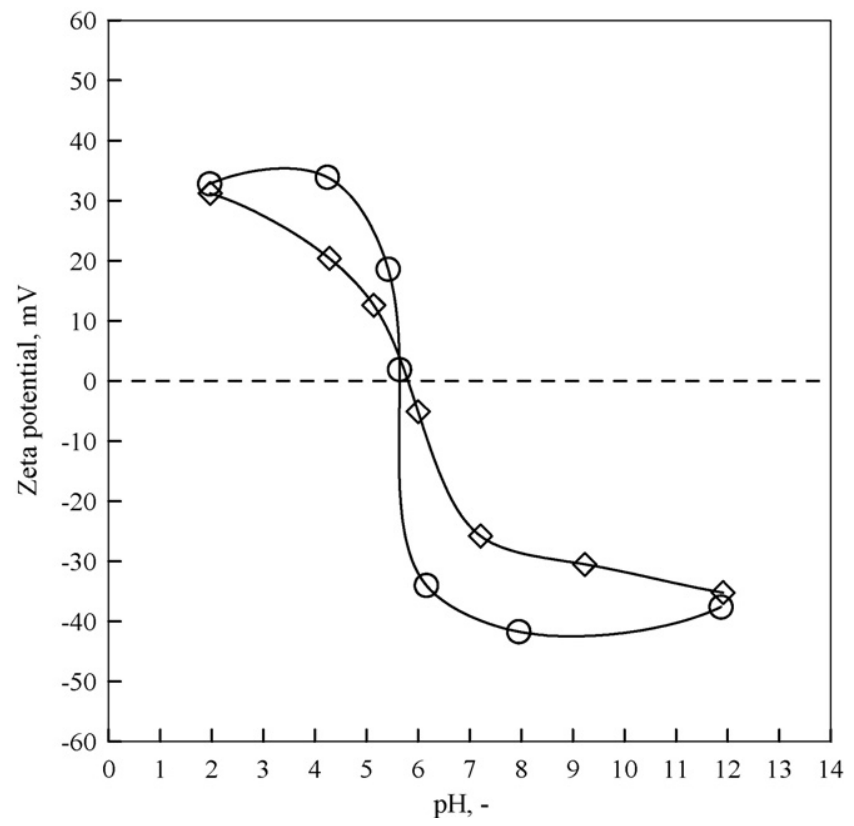

Fig. 8. Zeta potentials of $S P M Z$ as a function of $\mathrm{pH}$ value under various ionic strengths. $\bigcirc$ and $\diamond$ : Ionic strengths of 0.1 and $0.01 \mathrm{~N} \mathrm{NaNO}_{3}$, respectively.

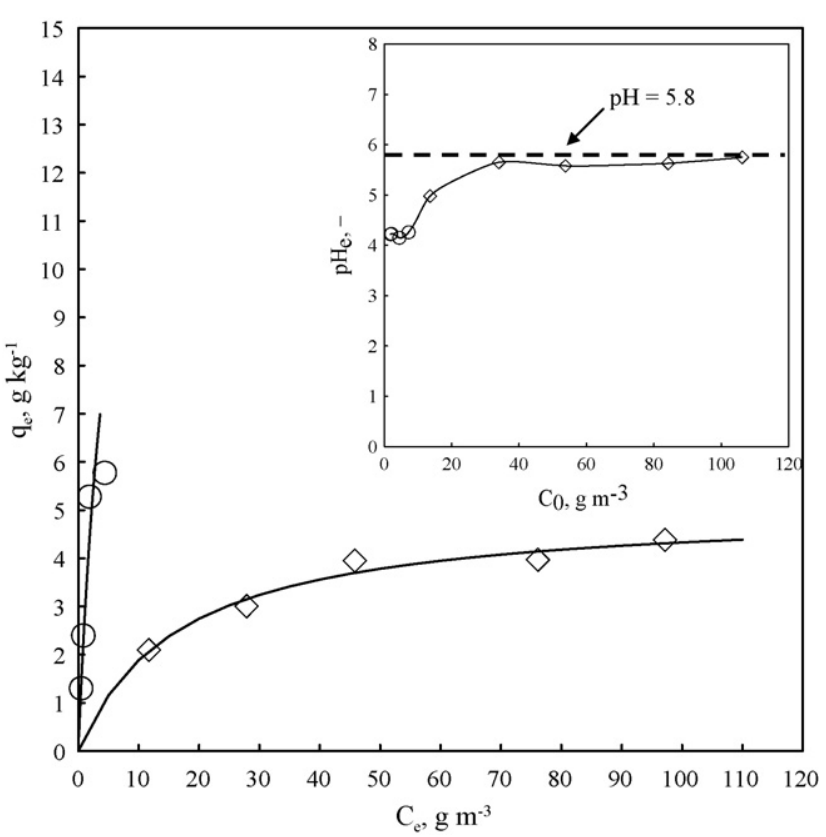

Fig. 9. Relationship between adsorption capacity and equilibrium $\mathrm{pH}$ value at an initial $\mathrm{pH}$ value of $4 . \bigcirc$ and $\diamond$ : Experimental data for $C_{0}$ of $1-7$ and $13.5-106 \mathrm{~g} \mathrm{~m}^{-3}$, respectively. -: Prediction with Langmuir isotherm.

ticle [27], wherein it was reported that the adsorption of sulfate only occurred on the positively charged surface of soil and materials. It is noted that the adsorption capacity is significantly reduced from 6 to $2 \mathrm{~g} \mathrm{~kg}^{-1}$ in the border between GI and GII, indicating that the increase of $\mathrm{pH}_{\mathrm{e}}$ from 4.2 of GI to 5.1 of GII markedly inhibits the adsorption of sulfate on SPMZ. It may be due to the cause that the sharp decrease of zeta potential of SPZM from $33 \mathrm{mV}$ at $\mathrm{pH}_{\mathrm{e}}$ of 4.2 to $13 \mathrm{mV}$ at $\mathrm{pH}_{\mathrm{e}}$ of 5.1 results in the great reduction of electrostatic attraction. Therefore, the $\mathrm{pH}_{\mathrm{e}}$ value plays a crucial role on the adsorption of sulfate on SPMZ.

\subsubsection{Adsorption isotherm}

The adsorption rate of sulfate on SPMZ under a fixed $\mathrm{pH}$ value of 4 and stirring speed of $200 \mathrm{rpm}$ in CSTR for various $C_{0}$ is shown in Fig. 10. The adsorption rate is very fast in $1 \mathrm{~min}$ under various $C_{0}$ and then gradually reaches equilibrium. It is interested to note that the fast adsorption rate for the adsorption of sulfate on SPMZ manifests the high external mass transfer rate for nano-sized adsorbents, which can greatly reduce the treatment time of the adsorption process. Furthermore, as the particle size is very small, the adsorption kinetics of the internal diffusion is not the necessary point for discussion in this study.

The most widely used two-parameter $\left(Q_{\mathrm{L}}\right.$ and $\left.K_{\mathrm{L}}\right)$ equation of Langmuir isotherm based on monolayer adsorption was adopted to describe the adsorption behavior of sulfate on SPMZ, as illustrated in

$q_{\mathrm{e}}=\frac{Q_{\mathrm{L}} K_{\mathrm{L}} C_{\mathrm{e}}}{1+K_{\mathrm{L}} C_{\mathrm{e}}}$

In the above description, $q_{\mathrm{e}}$ and $C_{\mathrm{e}}$ are the adsorbate concentrations in solid and liquid phases at equilibrium, respectively. $Q_{\mathrm{L}}$ and $K_{\mathrm{L}}$ are the Langmuir isotherm constants, in which the former and latter represent the monolayer adsorption capacity and adsorption equilibrium constant, respectively. The linear form of Langmuir isotherm $\left(C_{\mathrm{e}} / q_{\mathrm{e}}\right.$ versus $\left.C_{\mathrm{e}}\right)$ was used to obtain the values of $Q_{\mathrm{L}}$ and $K_{\mathrm{L}}$ with the slope and intercept yielding $1 /\left(\mathrm{Q}_{\mathrm{L}} K_{\mathrm{L}}\right)$ and $1 / \mathrm{Q}_{\mathrm{L}}$. In order to compare the adsorption capacity of SPMZ with commercial zirconia, nano-sized zirconia supplied by sigma (denoted as NCZ) was 


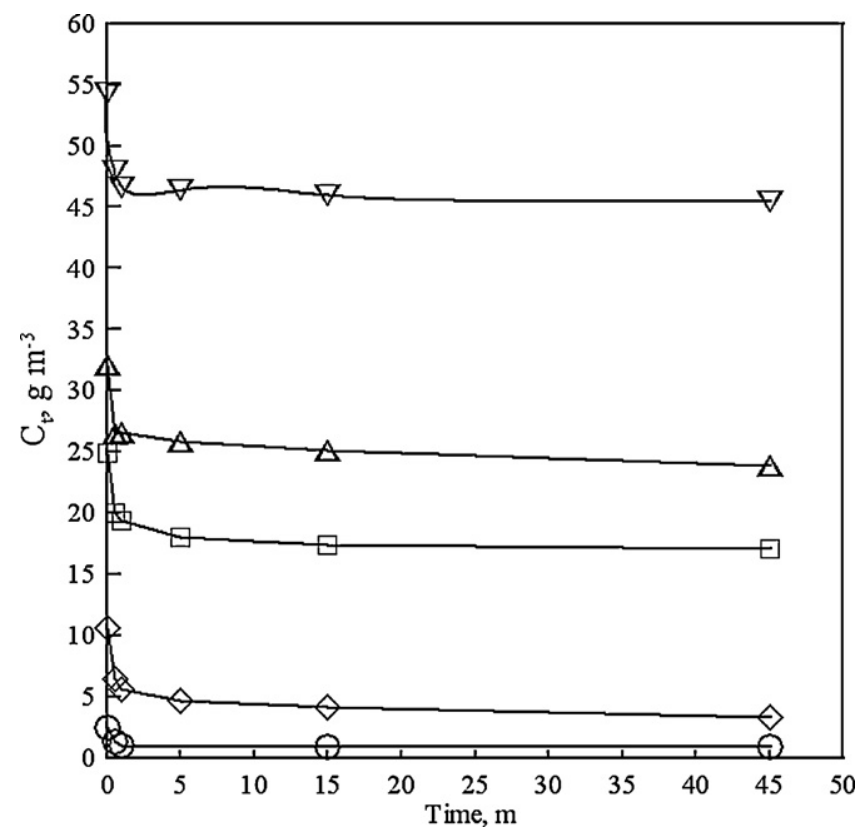

Fig. 10. Variations of concentrations $\left(C_{\mathrm{t}}\right)$ with time at various $C_{0}$ for the adsorption of sulfate on SPMZ under a constant $\mathrm{pH}$ value of $4 . \bigcirc, \diamond, \square, \triangle$ and $\nabla$ : Experimental data at $C_{0}$ of $2.5,10.6,24.9,32.1$ and $54.4 \mathrm{~g} \mathrm{~m}^{-3}$, respectively.

used as the reference sorbent in this study. The results of $q_{\mathrm{e}}$ versus $C_{\mathrm{e}}$ are shown in Fig. 11.

The correlation coefficients $\left(r^{2}\right)$ of experimental data fitting with the Langmuir isotherm for SPMZ and NCZ are 0.9822 and 0.9703, respectively, interpreting the Langmuir isotherm can well explain the adsorption data. The determined isotherm parameters of $Q_{\mathrm{L}}$ and $K_{\mathrm{L}}$ for SPMZ and NCZ are $9.29 \mathrm{~g} \mathrm{~kg}^{-1}$ and $0.50 \mathrm{~m}^{3} \mathrm{~g}^{-1}$ and $9.78 \mathrm{~g} \mathrm{~kg}^{-1}$ and $0.40 \mathrm{~m}^{3} \mathrm{~g}^{-1}$, respectively, indicating that the adsorption capac-

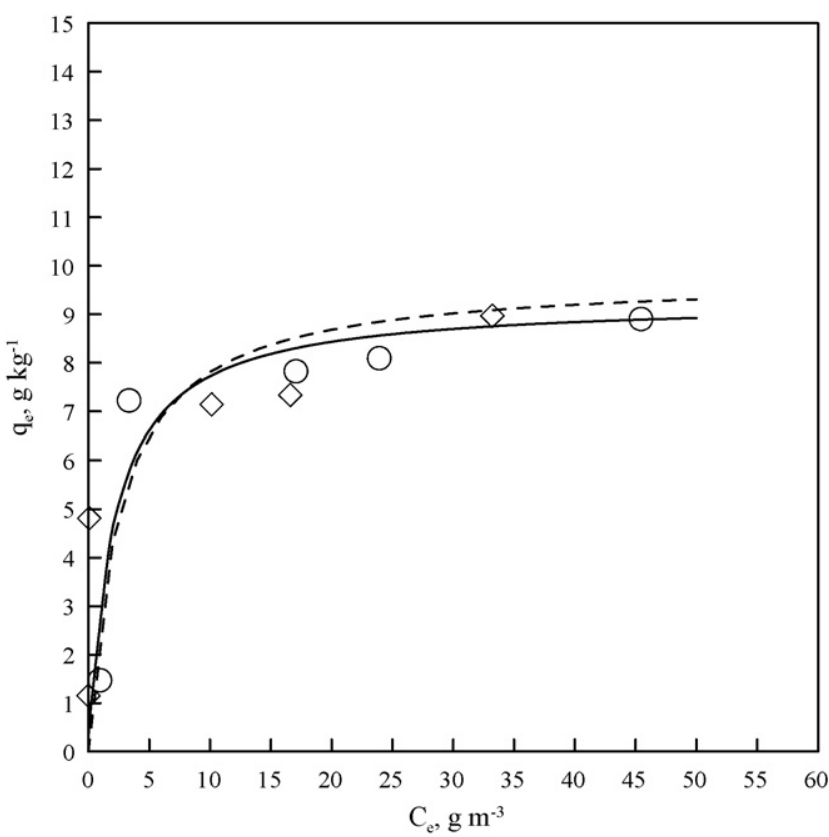

Fig. 11. $q_{\mathrm{e}}$ vs. $C_{\mathrm{e}}$ for the adsorptions of sulfate on SPMZ and $\mathrm{NCZ}$ at a fixed $\mathrm{pH}$ value of $4 . q_{\mathrm{e}}$ and $C_{\mathrm{e}}$ : Adsorbate concentrations in solid and liquid phases at equilibrium, respectively. $\bigcirc$ and $\diamond$ : Experimental data of SPMZ and NCZ, respectively. - and -- -: Predictions of experimental data of SPMZ and NCZ with Langmuir isotherm, respectively. ity $\left(Q_{\mathrm{L}}\right)$ of SPMZ is comparable to that of NCZ. Furthermore, a comparison of the adsorption capacities of the cases with $\mathrm{pH}_{\mathrm{e}}=4$ and $\mathrm{pH}_{\mathrm{e}}=5-5.8\left(\diamond\right.$ in Fig. $9, \mathrm{Q}_{\mathrm{L}}=5.05 \mathrm{~g} \mathrm{~kg}^{-1}, K_{\mathrm{L}}=0.06 \mathrm{~m}^{3} \mathrm{~g}^{-1}$ and $r^{2}=0.9917$ ) for SPMZ indicated that the former possesses almost twice adsorption capacity higher than that of latter. The adsorption of sulfate on SPMZ results mainly from the electrostatic attraction between the negative charged sulfate and positively charged surface, which agrees with that the $\mathrm{pH}$ value of solution almost dominates the adsorption capacity. The further possible reaction between sulfate and zirconia for a long-time period would need further investigation.

\section{Conclusions}

A novel superparamagnetic zirconia $\left(\mathrm{ZrO}_{2} / \mathrm{SiO}_{2} / \mathrm{Fe}_{3} \mathrm{O}_{4}, \mathrm{SPMZ}\right)$ material has been successfully synthesized and applied to remove sulfate from aqueous solution in this study. The crystal structure of zirconia on SPMZ is mainly composed of both tetragonal and monoclinic types. The adsorption capacity of sulfate on SPMZ and the zeta potential of SPMZ are rather sensitive to the $\mathrm{pH}$ value of the solution in the range of 4-5.8. The further adsorption of sulfate is restrained when the $\mathrm{pH}$ value of the solution is higher than the point of zero charge $\mathrm{pH}_{\mathrm{PZC}}$ of SPMZ. The adsorption capacity of sulfate on SPMZ under a fixed pH value of 4 can be comparable to that of commercially nanopowder of zirconia. Furthermore, the adsorption rate of sulfate on SPMZ is rather fast in $1 \mathrm{~min}$ and then gradually reaches the adsorption equilibrium. In conclusion, the novel superparamagnetic zirconia material synthesized in this study can be expected to have highly applicable potential in adsorption with its fast adsorption rate and easiness for the recovery using magnetic separation.

\section{Acknowledgements}

The authors thank for the National Science Council of Taiwan for the financial support under Grant NSC 94-2211-E-029-005 and the Powder Technology Laboratory of Chemical Engineering Department of Nation Taiwan University for the assistance in powder characterization.

\section{References}

[1] C.F. Chang, C.Y. Chang, W. Holl, Ind. Eng. Chem. Res. 42 (2003) 6904-6910.

[2] C.F. Chang, C.Y. Chang, W. Holl, J. Colloid Interface Sci. 272 (2004) 52-58.

[3] C.F. Chang, C.Y. Chang, W. Holl, M. Ulmer, Y.H. Chen, H.J. Gro $\beta$, Water Res. 38 (2004) 2559-2570.

[4] C.F. Chang, C.Y. Chang, K.E. Hsu, W. Holl, P.C. Chiang, J. Environ. Eng. Manage. 17 (2007) 311-318.

[5] W. Den, H.C. Liu, S.F. Chan, K.T. Kin, C. Huang, J. Environ. Eng. Manage. 16 (2006) 275-282.

[6] P.E. Diaz-Flores, R. Leyva-Ramos, J.R. Rangel-Mendez, M.M. Oritz, R.M. Guerrero-Coronado, J. Mendoza-Barron, J. Environ. Eng. Manage. 16 (2006) 249-257.

[7] C.K. Jain, I. Ali, Hydrol. Process 14 (2000) 261-270.

[8] L.C. Juang, C.C. Wang, C.K. Lee, T.C. Hsu, J. Environ. Eng. Manage. 17 (2007)29-38.

[9] C. Namasivayam, K. Prathap, J. Environ. Eng. Manage. 16 (2006) 267-274.

[10] C. Namasivayam, M.V. Sureshkumar, J. Environ. Eng. Manage. 17 (2007) 129-135.

[11] C. Papelis, P.V. Roberts, J.O. Leckie, Environ. Sci. Technol. 29 (1995) 1099-1108.

[12] S.R. Rudge, T.L. Kurtz, C.R. Vessely, L.G. Catterall, D.L. Williamson, Biomaterials 21 (2000) 1411-1420.

[13] Z.G. Peng, K. Hidajat, M.S. Uddin, J. Colloid Interface Sci. 271 (2004) 277-283.

[14] C.F. Chang, P.H. Lin, W. Holl, Colloids Surf. A-Physicochem. Eng. Aspects 280 (2006) 194-202.

[15] J.Y. Tseng, C.Y. Chang, Y.H. Chen, C.F. Chang, P.C. Chiang, Colloids Surf. APhysicochem. Eng. Aspects 295 (2007) 209-216.

[16] J.A. Blackwell, P.W. Carr, J. Chromatogr. 549 (1991) 43-57.

[17] N.Q. Minh, J. Am. Ceram. Soc. 76 (1993) 563-588.

[18] K. Tomishige, Y. Ikeda, T. Sakaihori, K. Fujimoto, J. Catal. 192 (2000) 355-362.

[19] J. Nawrocki, M.P. Rigney, A. McCormick, P.W. Carr, J. Chromatogr. A 657 (1993) 229-282.

[20] B.T. Holland, C.F. Blanford, A. Stein, Science 281 (1998) 538-540. 
[21] M.S. Wong, J.Y. Ying, Chem. Mater. 10 (1998) 2067-2077.

[22] L.M. Martinez, C.M. de Correa, J.A. Odriozola, M.A. Centeno, Catal. Today 107-108 (2005) 800-808.

[23] J.A. Wang, M.A. Valenzuela, J. Salmones, A. Vazquez, A. Garcia-Ruiz, X. Bokhimi, Catal. Today 68 (2001) 21-30.

[24] M.E. Alves, A. Lavorenti, Geoderma 118 (2004) 89-99.

[25] P.H. Lin, Adsorption of fluoride onto commercial activated alumina and novel magnetic fluoride selective nano-adsorbents from aqueous solutions, Master thesis, Graduate Institute of Environmental Engineering, National Taiwan University, Taipei, Taiwan, 2004.

[26] M.S. Hosseini, H. Rahiminegad, J. Anal. Chem. 61 (2006) 166-171.

[27] L. Charlet, N. Dise, W. Stumm, Agric. Ecosyst. Environ. 47 (1993) 87-102.
[28] R. Rietra, T. Hiemstra, W.H. van Riemsdijk, J. Colloid Interface Sci. 240 (2001) 384-390.

[29] S. Rose, Water Air Soil Pollut. 101 (1998) 333-347.

[30] S. Brunauer, L.S. Deming, W.E. Deming, E. Teller, J. Am. Chem. Soc. 62 (1940) 1723-1732.

[31] S. Lowell, J.E. Shields, Powder Surface Area and Porosity, 3rd ed., Chapman and Hall, London, UK, 1991

[32] X. Bokhimi, A. Morales, O. Novaro, M. Portilla, T. López, F. Tzompantzi, R. Gómez, J. Solid State Chem. 135 (1998) 28-35.

[33] L.T. Zhuravlev, Colloids Surf. A-Physicochem. Eng. Aspects 74 (1993) 71-90.

[34] V.V. Potapov, L.T. Zhuravlev, Glass Phys. Chem. 31 (2005) 661-670. 